\title{
Interferon-Alpha Restores the Deficient Expression of the Cytoadhesion Molecule Lymphocyte Function Antigen-3 by Chronic Myelogenous Leukemia Progenitor Cells
}

\author{
Gargi Upadhyaya," Susan C. Guba," Sharon A. Sih," Andrew P. Feinberg," Moshe Talpaz," \\ Hagop M. Kantarjian," Albert B. Deisseroth," and Stephen G. Emerson* \\ *Departments of Internal Medicine and Pediatrics, and Cell and Molecular Biology Program, University of Michigan, Ann Arbor, \\ Michigan 48109; $\ddagger$ Department of Genetics and Howard Hughes Medical Institute, University of Michigan, Ann Arbor, Michigan, 48109; \\ and §Department of Hematology, University of Texas M. D. Anderson Cancer Center, Houston, Texas 77030
}

\begin{abstract}
Hematopoietic cells from the malignant clone in chronic myelogenous leukemia (CML) maintain and expand a proliferative advantage over normal hematopoietic cells within the bone marrow. This advantage is often ameliorated or reversed in vivo by IFN $_{\alpha}$. Based upon earlier studies suggesting decreased adhesiveness of CML progenitor cells, we asked whether CML progenitor cells are deficient in their expression of the cytoadhesion molecule lymphocyte function antigen-3 (LFA-3, CD58) which is normally expressed on hematopoietic progenitors. Progenitor cells from untreated CML patients showed greatly reduced or absent LFA-3 expression, whereas progenitors from patients treated with IFN $\mathrm{N}_{\alpha}$ in vivo or in vitro expressed surface LFA-3 at more normal levels. LFA-3-deficient CML progenitor cells were unable to stimulate normal regulatory proliferative responses in autologous $T$ cells. We hypothesize that IFN $_{\alpha}$-sensitive LFA-3 deficiency reflects a cell surface cytoadhesion defect which may help explain adhesive abnormalities of CML progenitor cells in vitro and clonal proliferation in vivo. (J. Clin. Invest. 1991. 88:2131-2136.) Key words: adhesion • clonal expansion $\cdot$ stem cell
\end{abstract}

\section{Introduction}

The $(9 ; 22)$ Philadelphia translocation of chronic myelogenous leukemia $(\mathrm{CML})^{1}$ was the first described nonrandom translocation in malignancy, and has now been molecularly identified with the structurally and functionally abnormal chimeric protooncogene bcr-abl (1-5). CML evolves clinically to more advanced stages through the sequential acquisition of additional cytogenetic abnormalities, a pattern which has recently been demonstrated in common solid tumors as well (6-8).

Despite these important advances in our understanding of CML, the process by which the affected malignant clone maintains its proliferative advantage in vivo remains unknown, de-

Address correspondence to Stephen Emerson, M.D., Ph.D., 1150 West Medical Center Drive, 5510 MSRB I, Ann Arbor, MI 48109-0680.

Received for publication 15 February 1991 and in revised form 7 June 1991.

1. Abbreviations used in this paper: APLR, autologous proliferative response; BFU-E, erythroid burst forming units; CML, chronic myelogenous leukemia; IMDM, Iscove's modified Dulbecco's medium; LFA3, lymphocyte function antigen-3; PI, phosphatidyl-inositol; PNH, paroxysmal nocturnal hemoglobinuria.

J. Clin. Invest.

(c) The American Society for Clinical Investigation, Inc.

0021-9738/91/12/2131/06 \$2.00

Volume 88, December 1991, 2131-2136 spite extensive in vitro investigation. When grown in shortterm colony forming assays, CML progenitor cells appear to display the same dependence on hematopoietic growth factors as do normal progenitors. In long-term liquid cultures, progenitors arising from the CML clone survive less well than do normal progenitors, and actually disappear over time leaving behind only normal cells (9). Finally, while in vivo IFN ${ }_{\alpha}$ treatment ameliorates or totally reverses the proliferative advantage of the CML clone, with $15-25 \%$ of cases experiencing complete cytogenetic remission (10), no in vitro assay to date has identified a selective effect of IFN $\mathrm{N}_{\alpha}$ on CML versus normal hematopoietic cells.

Several lines of circumstantial evidence suggests that CML progenitor cells are deficient in their expression of cell surface cytoadhesion molecules. First, Gordon et al. found that CML progenitor cells adhered poorly to bone marrow stromal monolayers in vitro, and more recently have suggested that normal progenitor cell stromal adhesion is mediated through a phosphatidyl-inositol(PI)-linked surface receptor $(11,12)$. Next, the cytochemical hallmark of CML is decreased expression of the PI-linked ectoenzyme leukocyte alkaline phosphatase (13). Finally, lymphocyte function associated antigen three (LFA-3, CD58) whose cell surface expression can be linked through PI, has been found to be underexpressed in EBV-transformed cell lines, leading to their escape from immune surveillance and suppression by autoreactive $T$ lymphocytes (14). Taken together, these observations suggest that deficient expression of critical progenitor cell cytoadhesion molecules, including those which include PI-linked isoforms such as LFA-3, might contribute to the pathophysiologic clonal expansion of the CML clone in vivo.

We therefore asked whether CML progenitor cells bear cell surface LFA-3 as detectable in a solid phase immunoabsorption assay. Our results demonstrate that CML progenitor cells are deficient in their expression of LFA-3, and suggest that IFN $_{\alpha}$ treatment in vivo and in vitro restores deficient LFA-3 expression. In addition, the data indicate that CML cells indeed fail to stimulate autoimmunoregulatory $T$ cell responses characteristic of normal bone marrow progenitor cells.

\section{Materials}

Bone marrow mononuclear cells. Clinical samples used in this study were obtained coincident to routine diagnostic procedures used to evaluate CML patients at the M.D. Anderson Cancer Center, under a protocol approved by the M.D. Anderson Cancer Center Human Subjects Committee. Normal bone marrow was aspirated under local anesthesia from volunteers following informed consent, under a protocol approved by the University of Michigan Institutional Review Board. Mononuclear cells were prepared by centrifugation over Ficoll-Hypague (Sigma Chemical Co., St. Louis, MO), 1.077. After three washes in 
Iscove's modified Dulbecco's medium (IMDM) supplemented with 2\% FCS (Hyclone Laboratories Inc., Logan, UT), adherent cells were removed by overnight incubation at $10^{6} \mathrm{cells} / \mathrm{ml}$ in IMDM $+20 \%$ FCS over 100-mm plastic dishes (Corning Glass Inc., Corning, NY).

Separation of $\mathrm{LFA}-3(\mathrm{CD} 58)^{+}$and ${ }^{-}$cells. Nonadherent bone marrow mononuclear cells were separated into LFA-3(CD58) ${ }^{+}$and fractions by panning $(15,16)$. Briefly, the cells were suspended in IMDM plus 5\% FCS in the presence of mouse anti-human LFA-3 (TS2.9 ascites, generously provided by Drs. Carol Clayberger and Alan Krensky, Stanford University, Palo Alto, CA) for $1 \mathrm{~h}$ at $4^{\circ} \mathrm{C}$, washed, resuspended in PBS plus 5\% FCS, and incubated at $4^{\circ} \mathrm{C}$ over $100-\mathrm{mm}$ plastic tissue culture dishes coated with $5 \mathrm{ml} \mathrm{rabbit} \mathrm{anti-mouse} \mathrm{Ig} \mathrm{(100}$ $\mu \mathrm{g} / \mathrm{ml}$; Zymed Labs, Inc., South San Francisco, CA). After $1 \mathrm{~h}$, the plates were gently tipped and nonadherent, LFA- ${ }^{-}$cells removed by aspiration. After once gently rinsing the plates, $5 \mathrm{ml}$ IMDM plus $5 \%$ FCS was added and the adherent cells incubated for $30 \mathrm{~min}$ at $37^{\circ} \mathrm{C}$ under $5 \% \mathrm{CO}_{2}$. The previously adherent, $\mathrm{LFA}-3^{+}$cells were then recovered by aspiration and the use of a rubber policeman. Analogous procedures were followed to isolate ${ }^{+}$and ${ }^{-}$cells for other antigens, using $\alpha$ HLA-DR (300 $\mu \mathrm{g} / 10^{6}$ cells; Becton Dickinson and Co., Cockeysville, MD), $\alpha$ HLA-DQ ( $\alpha$ Leu-10, $500 \mu \mathrm{g} / 10^{6}$ cells; Becton Dickinson), $\alpha \mathrm{CD} 15\left(\alpha\right.$ Leu-M1, $300 \mu \mathrm{g} / 10^{6}$ cells; Becton Dickinson), $\alpha$ glycophorin $\mathrm{A}\left(4 \mathrm{~F} 7,100 \mu \mathrm{g} / 10^{6}\right.$ cells, generously provided by Dr. William Bigbee, Lawrence Livermore Laboratories), $\alpha$ LFA- $1 \alpha$ chain/CD11a and $\alpha$ LFA-1b chain/CD18 (1/200 hybridoma supernatant, both generously provided by Drs. Carol Clayberger and Krensky).

Methylcellulose cultures. Each fraction was cultured in $0.9 \%$ methylcellulose supplemented with $10 \%$ deionized BSA and $30 \%$ FCS in the presence of interleukin $3(10 \mathrm{ng} / \mathrm{ml}$, generously provided by Dr. Steven Clark, Genetics Institute, Cambridge, MA) and erythropoietin (2 U/ ml, Amgen Biologicals, Thousand Oaks, CA), and erythroid (burst forming unit-erythroid-derived), myeloid (granulocyte-macrophage colony forming unit-derived), and multilineage (granulocyte-erythroid-macrophage-megokaryocyte colony forming unit-derived) colonies enumerated on day 17.

Interferon treatment in vitro. Nonadherent CML bone marrow mononuclear cells were incubated at $10^{6} \mathrm{cells} / \mathrm{ml}$ in IMDM plus $20 \%$ FCS supplemented with 0-200 U/ml IFN ${ }_{\alpha}$ (Schering Corp., Kenilworth, $\mathrm{NJ}$ ) for $24 \mathrm{~h}$ at $37^{\circ} \mathrm{C}$ under $5 \% \mathrm{CO}_{2}$. Aliquots were withdrawn at $0,4,12$, and $24 \mathrm{~h}$, the cells separated into LFA- $3^{+}$and LFA- $3^{-}$fractions by panning, and progenitor cells enumerated by methylcellulose culture in the presence of IL-3 plus Epo. The data are presented as progenitor cells per $10^{5}$ cell before fractionation.

Detection of the bcr-abl rearrangement by polymerase chain reaction (PCR) in individual colonies. Ethidium bromide-stained Nusieve/ agarose $(3 \% / 1 \%)$ gels of PCR products, obtained from reverse-transcribed mRNA from myeloid colonies plucked from methylcellulose cultures. Methods: Nonadherent bone marrow cells from a CML patient whose untreated progenitor cells were $92 \%$ LFA- $3^{-}$were incubated with $\mathrm{IFN}_{\alpha}$ for $24 \mathrm{~h}$, then fractionated into LFA-3 ${ }^{-}$and LFA-3 ${ }^{+}$ fractions by panning, and each fraction cultured for $14 \mathrm{~d}$ in methylcellulose. $96 \%$ of the colonies were detected in the LFA-3 ${ }^{+}$fraction. 12 well separated LFA- $3^{+}$colonies were plucked with a $10 \mu$ l glass pipette, each colony was washed in PBS, and RNA was extracted essentially as described (17). Methylcellulose from adjacent portions of the culture plates was plucked and processed in parallel, and RNA from the K562 cell line and normal human bone marrow were processed as positive controls as well. cDNA was synthesized with reverse transcriptase using a specific primer present in both normal and rearranged bcr messages. The cDNA was divided in half for assay of both normal abl and bcr abl. First round PCR primers and nested primers for bcr-abl were as described (17), and nested primers for second round normal abl amplification were GCTCCGGCCCGATCGTTCGCTTGGCGCAAA for exon 1a, GACCAAAGAAGGCCAAGCTTGCCTGCCCTG for exon $1 \mathrm{~b}$, and CTCAGACCCTGAGGCTCAAAGTCAGATGCT for $3^{\prime}$ abl sequence. The polymerase chain reaction $(18,19)$ was performed with Taq polymerase by denaturation at $94^{\circ} \mathrm{C}$ for $1 \mathrm{~min}$ and primer exten- sion at $72^{\circ} \mathrm{C}$ for $2 \mathrm{~min}$, for 35 rounds with no annealing step. In $11 / 12$ samples normal abl as well as bcr-abl could be detected on an ethidium bromide-stained gel. DNA from all 12 colonies was transferred after electrophoresis to Genescreen and hybridized with end-labelled internal $3^{\prime}$ abl oligonucleotide, at $50^{\circ} \mathrm{C}$ by the method of Church and Gilbert (20), to confirm the identity of the visualized PCR products and to score samples in which the PCR product could not be visualized directly on a gel.

Stimulation of autologous proliferating $T$ cells in response to progenitors (APLR). Highly enriched CML or normal bone marrow progenitor cells were prepared by removing contaminating nonprogenitor cells ( $\mathrm{T}$ cells, B cells, NK cells, myeloid and erythroid precursors) by negative immunoselection on plastic dishes $(15,16)$, and irradiated with $20 \mathrm{~Gy} .10^{5}$ autologous $\mathrm{CD}^{+} \mathrm{T}$ cells were incubated with $10^{5}$ irradiated progenitor cells for $8 \mathrm{~d}$, the cultures pulsed with ${ }^{3} \mathrm{HTdR}$ for $16 \mathrm{~h}$, and the cells were harvested. T cell proliferation was measured by the stimulation index, i.e., the ratio of ${ }^{3} \mathrm{H}$ incorporation into $\mathrm{T}$ cells stimulated with progenitor cells, versus ${ }^{3} \mathrm{H}$ incorporation into unstimulated $\mathrm{T}$ cells $(21)$

\section{Results}

CML progenitor cells are deficient in the expression of cell surface LFA-3 (CD58). Bone marrow mononuclear cells from a normal donor, and from a patient with newly diagnosed, untreated CML, were labelled with murine anti-human LFA-3, or anti-human LFA- 1 or anti-HLA-DR, and separated by panning into antibody positive and negative cell fractions (15-16). Each fraction was then cultured in methylcellulose, and progenitor cells measured by enumeration of unilineage and multilineage hematopoietic colonies at $17 \mathrm{~d}$. The normal bone marrow progenitor cells were uniformly LFA- ${ }^{+}$, with $86 / 86$ erythroid burst forming units (BFU-E), 120/122 granulocytemacrophage colony forming units (CFU-GM), and 14/14 multilineage colony forming cells (CFU-GEMM) partitioning into the LFA $-3^{+}$fraction. In contrast, $>95 \%$ of the progenitor cells from the CML bone marrow sample partitioned into the LFA$3^{-}$fraction (Table I). Similar results were obtained in 10 normal controls, whose progenitor cells were nearly all LFA $-3^{+}$in this assay, and in 17 additional patients with untreated stable phase CML, most or all of whose progenitor cells were LFA-3 ${ }^{-}$. This underexpression of cell surface LFA-3 appeared not to be

Table I. Fractionation of Normal and CML Progenitor Cells Via the Expression of Cell Surface LFA-3

\begin{tabular}{ccrrr}
\hline & \multicolumn{2}{c}{ Colonies per $10^{5}$ Cells* } & & \\
\cline { 2 - 3 } Sample & $\begin{array}{c}\text { Bone } \\
\text { marrow fraction }\end{array}$ & BFU-E & CFU-GM & CFU-GEMM \\
\hline Normal BM & LFA-3 $^{+}$ & 86 & 120 & 14 \\
& LFA-3 $^{-}$ & 0 & 2 & 0 \\
Untreated CML & LFA-3 $^{+}$ & 12 & 14 & 0 \\
& LFA-3 $^{-}$ & 93 & 81 & 7 \\
& & & & \\
\hline
\end{tabular}

* Nonadherent bone marrow mononuclear cells were separated into LFA $-3^{+}$and - fractions by panning. The + and - fractions were cultured in $0.9 \%$ methylcellulose, and erythroid (burst forming unit-erythroid-derived), myeloid (granulocyte-macrophage colony forming unit-derived), and multilineage (granulocyte-erythroid-macrophage-megokaryocyte colony forming unit-derived) colonies enumerated on day 17 . The data are presented based on $10^{5}$ cells before LFA-3 fractionation. 
caused by the proliferative bone marrow state of these patients per se, as progenitor cells from three patients with nonleukemic, reactive leukocytosis were $100 \%$ LFA- $^{+}$(Fig. 1). This disparity between CML and normal progenitor cell surface antigen expression was not found for several other cell surface proteins expressed on bone marrow cells, including LFA-1 and HLA-DR (Table II). Untreated stable phase CML hematopoietic progenitor cells, therefore, are relatively LFA-3 deficient compared with normal nonleukemic progenitor cells.

Progenitor cells from CML patients treated with interferon $\alpha$ express partially or fully normalized LFA-3 in vivo. Since the treatment of CML with IFN ${ }_{\alpha}$ results in amelioration or reversal of the proliferative advantage of the CML clone in vivo (12), we next examined bone marrow samples from CML patients being treated with IFN ${ }_{\alpha}$. In contrast to the CML patients before treatment, IFN $\mathrm{N}_{\alpha}$-treated CML patients displayed partially or completely restored surface LFA-3 expression, with 30-100\% of progenitor cells recovered in the LFA-3 ${ }^{+}$fraction (Fig. 1, final column). Individual CML patients were then studied both before and after treatment with IFN $\mathrm{N}_{\alpha}$, to determine if progenitor cell surface LFA-3 expression could be amplified over time following treatment. Progenitor cell surface LFA-3 expression was increased in each of three cases studied, to variable extents, after 3-6 mo of therapy (Fig. 2). These data suggested that treatment with $\mathrm{IFN}_{\alpha}$ might partially or completely reverse LFA-3 deficiency on the CML progenitor cells.

Interferon $\alpha$ reverses $C M L$ progenitor cell $L F A-3$ deficiency in vitro. These marrow samples from IFN $_{\alpha}$-treated CML patients, however, might have contained increased and variable percentages of normal, nonleukemic progenitor cells. Therefore, the observed restoration of progenitor cell LFA-3 expression might have been simply due to sampling of large numbers of nonleukemic progenitors that had been selected in vivo over months of IFN $\mathrm{N}_{\alpha}$ therapy. We therefore asked whether IFN

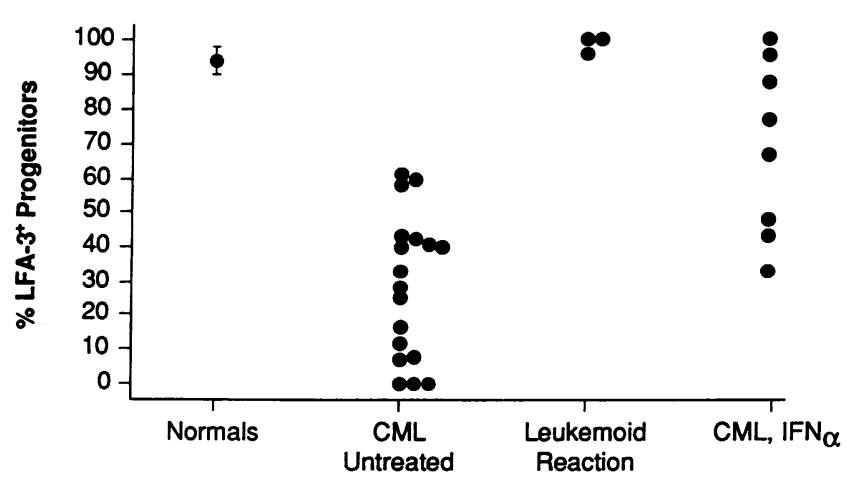

Figure 1. LFA-3 expression on CML progenitor cells. Nonadherent bone marrow mononuclear cells from 10 normal donors $(A), C M L$ patients not treated with $\operatorname{IFN}_{\alpha}(B), \mathrm{IFN}_{\alpha}$-treated CML patients $(C)$, or patients with nonleukemic elevations in neutrophil counts $(D)$ were separated into LFA-3 ${ }^{+}$and LFA-3- fractions by panning. Each fraction was cultured in methylcellulose, and erythroid (burst forming unit-erythroid-derived), myeloid (granulocyte-macrophage colony forming unit-derived) and multilineage (granulocyte-erythroid-macrophage-megokaryocyte colony forming unit-derived) colonies enumerated on day 17. Data are presented as the percentage of total (BFU-E + CFU-GM + CFU-GEMM) present in the LFA- ${ }^{+}$fraction. Progenitor cell surface LFA-3 was detected in this assay on $93 \pm 3 \%$ of normal progenitors.
Table II. Expression of Cell Surface Antigens on Normal and CML Progenitor Cells

\begin{tabular}{lcc}
\hline \multirow{2}{*}{$\begin{array}{c}\text { Cell surface } \\
\text { antigen (antibody) }\end{array}$} & \multicolumn{2}{c}{$\%+$ Bone marrow progenitors } \\
\cline { 2 - 3 } & CML BM & Normal BM \\
\hline & $n=7$ & $n=10$ \\
Gpn A & $0 \pm 0^{*}$ & $0 \pm 0$ \\
HLA-DR & $88 \pm 7$ & $95 \pm 4$ \\
HLA-DQ & $9 \pm 6$ & $4 \pm 3$ \\
CD34 & $96 \pm 3$ & $98 \pm 2$ \\
CD15 & $5 \pm 5$ & $7 \pm 4$ \\
LFA-1 $\alpha /$ CD11a & $11 \pm 6$ & $9 \pm 4$ \\
LFA-1 $\beta / C D 18$ & $6 \pm 3$ & $7 \pm 3$ \\
LFA-3/CD58 & $21 \pm 7$ & $93 \pm 3$ \\
\end{tabular}

* Percentage of total BFU-E + CFU-GM + CFU-GEMM recovered in the adherent fraction after panning as described in Table I, using the primary murine monoclonal antibodies to the specified epitopes. The data presented are means \pm SD for analyses from $7 \mathrm{CML}$ and 10 normal bone marrow samples.

could reverse deficient LFA-3 expression in vitro, before clonal selection could occur. Progenitor cells from an untreated CML patient were incubated in $200 \mathrm{U} / \mathrm{ml} \mathrm{IFN}_{\alpha}$, the peak plasma dose achieved after subcutaneous administration in vivo, for up to $24 \mathrm{~h}$, fractionated into LFA- $3^{+}$and LFA-3- cells by panning, and plated in methylcellulose. Whereas before IFN $_{\alpha}$ treatment, $80 \%$ of BFU-E, $83 \%$ of CFU-GM, and $90 \%$ of CFUGEMM were LFA-3- $^{-}$, after $24 \mathrm{~h}$ in vitro IFN $_{\alpha}$ incubation $75 \%$ of BFU-E, $68 \%$ of CFU-GM, and $80 \%$ of CFU-GEMM were $\mathrm{LFA}^{+}{ }^{+}$(Fig. 3). Moreover, while the absolute densities of

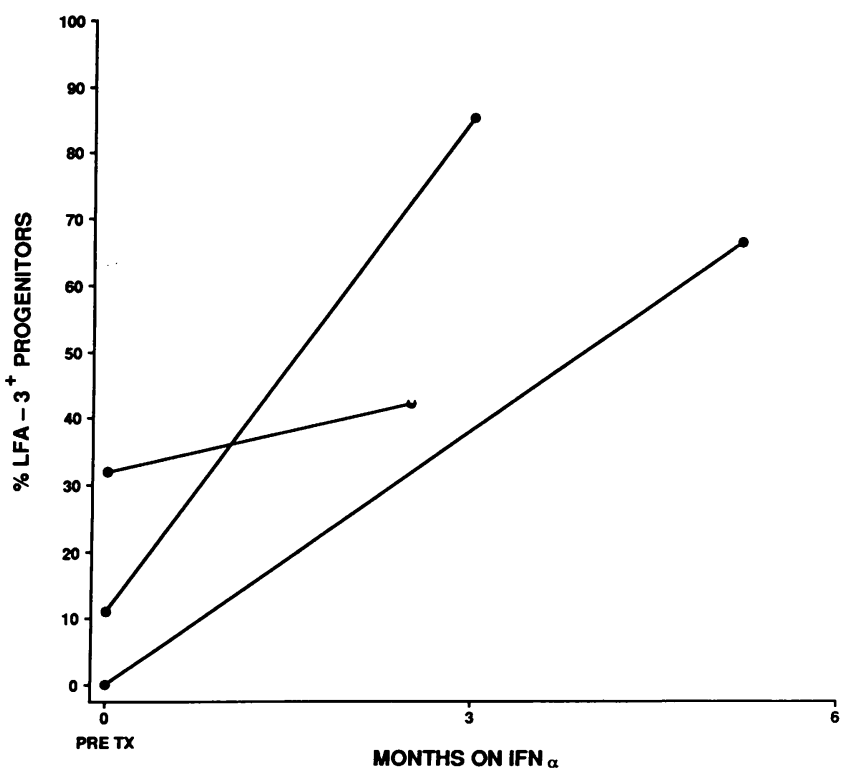

Figure 2. Response of progenitor cell LFA-3 expression to IFN ${ }_{\alpha}$ treatment in vivo. Bone marrow samples were obtained from three patients both before and after several months of treatment with IFN in vivo, and progenitor cells were analyzed for their expression of LFA-3 as described in Methods and in Fig. 1. 


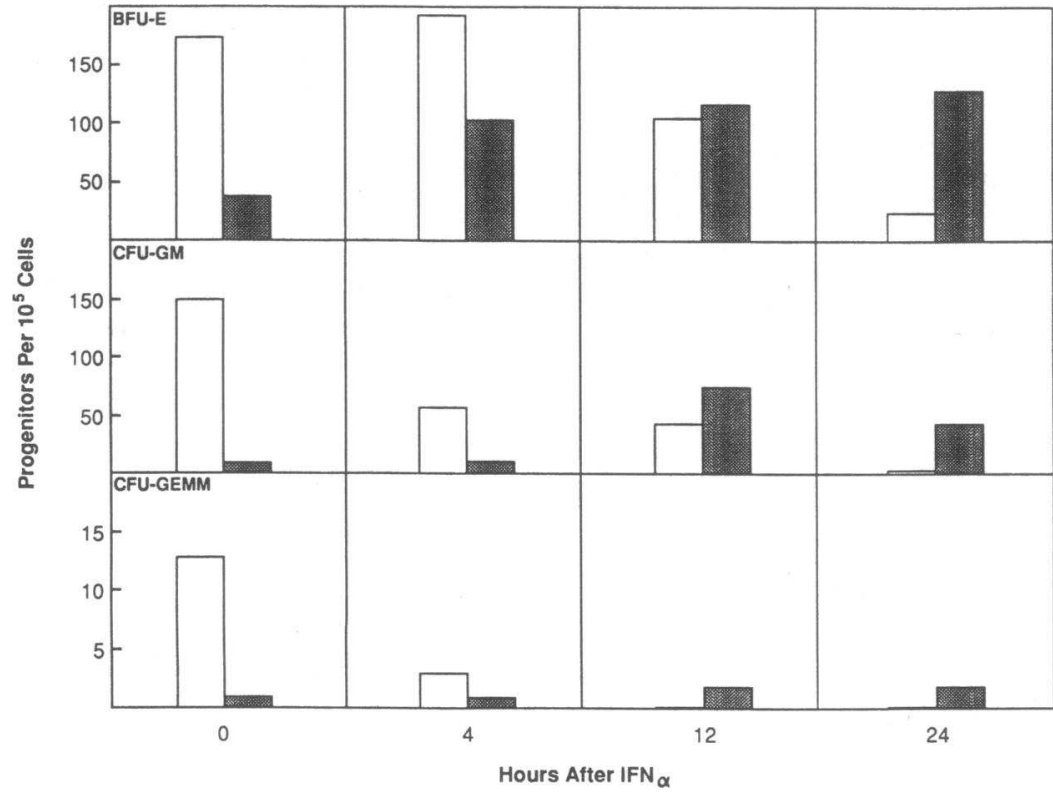

Figure 3. Pharmacologic doses of IFN ${ }_{\alpha}$ induces LFA-3 expression on CML progenitors in vitro: time course. Nonadherent CML bone marrow mononuclear cells were incubated at $10^{6}$ cells $/ \mathrm{ml}$ in IMDM plus $20 \%$ FCS supplemented with $200 \mathrm{U} / \mathrm{ml} \mathrm{IFN}_{\alpha}$ for $24 \mathrm{~h}$ at $37^{\circ} \mathrm{C}$ under $5 \% \mathrm{CO}_{2}$. Aliquots were withdrawn at 0 , 4,12 , and $24 \mathrm{~h}$, the cells separated into LFA- $3^{+}$and LFA-3- fractions by panning, and progenitor cells enumerated by methylcellulose culture in the presence of IL-3 plus Epo. The data are presented as progenitor cells (BFU-E + CFU-GM + CFU-GEMM) per $10^{5}$ cells before fractionation; ( $\left(\right.$ ), LFA-3 $^{-}$progenitors, ( 1 ) $\mathrm{LFA}-3^{+}$progenitors. Unlabelled CML bone marrow mononuclear cells treated in parallel with IFN ${ }_{\alpha}$ did not adhere to RAMIg coated plates (data not shown in figure).
LFA-3- progenitor cells did fall during this incubation, the concentration of $\mathrm{LFA}-3^{+}$progenitors rose, suggesting that increased LFA-3 expression was caused not simply by rapid selective in vitro toxicity to CML progenitors, but by induction of surface LFA-3 expression on previously LFA-3- progenitor cells. This LFA-3 inductive effect was seen at IFN ${ }_{\alpha}$ concentrations from 50-1,000 U/ml, which encompasses peak and trough levels obtained during in vivo patient treatment with IFN $_{\alpha}$ (Fig. 4). Similar results were obtained in six additional untreated CML patients, with progenitor cell LFA-3 expression increased from $0-13 \%$ to $31-96 \%$ (Table III).

Despite these kinetic and quantitative data, we wished to definitively exclude the possibility that IFN $\mathrm{I}_{\alpha}$ treatment in vitro was selecting for the growth of normal over leukemic progenitor cells in the LFA- ${ }^{+}$fraction. In these studies, hematopoietic

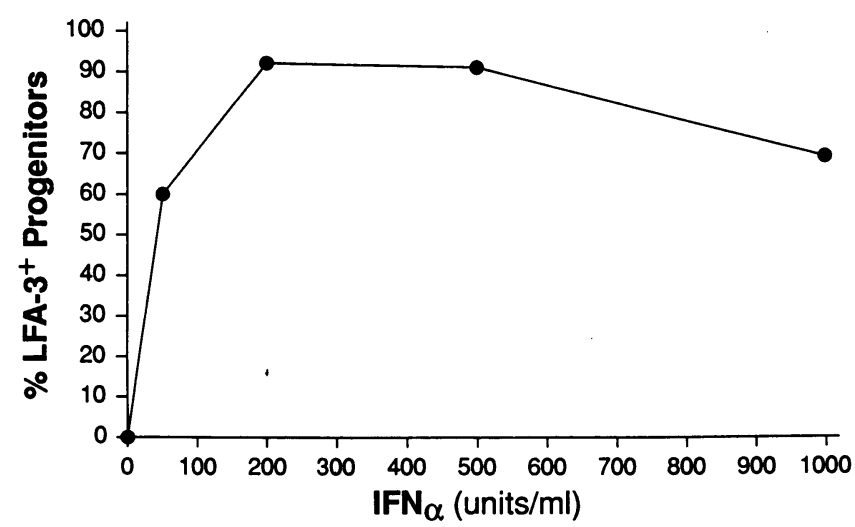

Figure 4. Pharmacologic doses of $\mathrm{IFN}_{\alpha}$ induces LFA-3 expression on CML progenitors in vitro: IFN $\mathrm{N}_{\alpha}$ dose response. Nonadherent bone marrow mononuclear cells were cultured at $10^{6}$ cells $/ \mathrm{ml}$ in the presence of $0,50 \mathrm{U}, 200 \mathrm{U}$, and $1,000 \mathrm{U} / \mathrm{ml} \mathrm{IFN}_{\alpha}$ for $24 \mathrm{~h}$. The cells were then fractionated into LFA- $3^{+}$and LFA- $3^{-}$cells by panning, and the + and - fractions cultured in the methylcellulose with IL-3 and Epo. The data are presented as percent (BFU-E + CFU-GM + CFUGEMM) in the LFA- $3^{+}$fraction. colonies were grown in methylcellulose, individual colonies were plucked and suspended in PBS, and RNA extracted and split into two aliquots. Reverse transcriptase polymerase chain reaction was used to amplify specific message for abl and bcrabl from the two aliquots. In this assay, RNA from colonies containing cells bearing the $\mathrm{Ph}$ chromosomal translocation would contain both abl and bcr-abl mRNAs, while colonies from normal hematopoietic progenitors would contain only abl but not bcr-abl mRNAs. The results revealed that RNA analysis of individual colonies plucked from the LFA $-3^{+}$fraction following in vitro interferon treatment confirmed that each colony expressed the characteristic bcr-abl transcript as well as the normal abl transcript (Fig. 5). Thus the LFA-3 ${ }^{+}$ progenitor cells arising after IFN $\mathrm{N}_{\alpha}$ treatment in vitro are indeed leukemic, and therefore reversion of deficient LFA-3 expres-

Table III. Alpha Interferon Induces LFA-3 Expression on CML Progenitor Cells In Vitro

\begin{tabular}{ccc}
\hline \multicolumn{3}{c}{ Percent LFA-3 $^{+}$progenitors* } \\
\hline Patient number & Untreated & Post-IFN $_{\alpha}$ \\
\hline 1 & 16 & 84 \\
2 & 0 & 32 \\
3 & 8 & 96 \\
4 & 0 & 61 \\
5 & 0 & 31 \\
6 & 0 & 41 \\
7 & 13 & 67 \\
\hline
\end{tabular}

* Percent (BFU-E + CFU-GM + CFU-GEMM) in the LFA-3 ${ }^{+}$fraction, after separation of nonadherent bone marrow mononuclear cells into LFA $3^{+}$and LFA-3- fractions, as in Table I. Each patient's bone marrow was studied immediately and after incubation for $24 \mathrm{~h}$ in IMDM plus $20 \% \mathrm{FCS}$ in the presence of $200 \mathrm{U} / \mathrm{ml} \mathrm{IFN} \mathrm{N}_{\alpha}$. Incubation for $24 \mathrm{~h}$ in IMDM/FCS without IFN $\mathrm{N}_{\alpha}$ did not increase LFA-3 expression (data not shown in table). Incubation of normal bone marrow progenitor cells $(n=4)$ in the presence of 50-200 U/ml IFN $\alpha$ did not change LFA-3 expression ( $96 \pm 4$ pre-IFN ${ }_{\alpha}, 95 \pm 7$ post-IFN ${ }_{\alpha}$ ). 

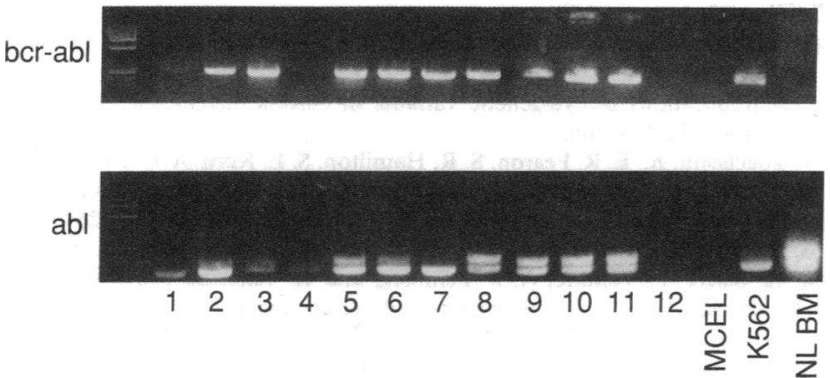

Figure 5. Detection of the bcr-abl rearrangement by PCR in individual LFA- $3^{+}$colonies from CML bone marrow cultured with IFN $_{\alpha}$ in vitro. Ethidium bromide-stained Nusieve/agarose (3\%/1\%) gels of PCR products, obtained from reverse transcribed mRNA from myeloid colonies plucked from methylcellulose cultures. In 11/12 samples normal abl as well as bcr-abl could be detected on an ethidium bromide-stained gel. DNA from all 12 colonies was transferred after electrophoresis to Genescreen and analyzed for the presence of abl or bcr-abl transcripts by alkaline Southern hybridization.

sion in vitro parallels the antiproliferative and anticlonal eIfects of IFN ${ }_{\alpha}$ in vivo.

CML progenitor cells fail to stimulate autologous $T$ cell proliferation. We have recently demonstrated that a subset of normal human $\mathrm{T}$ cells does proliferate when exposed to cycling autologous bone marrow progenitor cells, and that these autoreactive $T$ cells suppress autologous hematopoiesis. This autologous proliferative response to progenitors is specific for $\mathrm{CD} 34^{+}$ progenitor cells and is completely blocked by either anti-CD2 or anti-LFA-3 antibodies in vitro (21). We therefore asked whether CML LFA-3 deficiency was accompanied by failure of CML progenitor cells to stimulate a T cell APLR. Highly enriched progenitor cells were prepared from CML patients and normal donors, irradiated to $20 \mathrm{~Gy}$, and incubated with autologous $\mathrm{CD5}^{+} \mathrm{T}$ cells for $8 \mathrm{~d}$. Whereas progenitor cells from normal volunteers, and from patients with reactive leukocytosis (leukemoid reactions) stimulated a brisk APLR, untreated CML patients failed to stimulate any detectable APLR, and IFN ${ }_{\alpha}$-treated CML patients stimulated variable APLR responses (Fig. 6). These data demonstrate that CML progenitor cells fail to stimulate autoreactive $\mathrm{T}$ cells, which was predicted from their underexpression of cell surface LFA-3.

\section{Discussion}

These data indicate that CML progenitor cells are deficient in their expression of the cell surface cytoadhesion molecule LFA-3 (CD58). This deficiency appears to be ameliorated in patients treated with interferon $\alpha$. Moreover, treatment of CML bone marrow with IFN ${ }_{\alpha}$ in vitro reverses the LFA-3 defect over the course of $24 \mathrm{~h}$, indicating that the effects observed on patients treated with IFN $\mathrm{N}_{\alpha}$ are not simply the result of clonal selection in vivo.

LFA-3 is an extremely widely expressed cell surface protein, whose only known function is as the binding ligand for the $T$ cell surface protein $\operatorname{CD} 2(22,23)$. Its presence is thought to stabilize the interactions between $\mathrm{T}$ cells and their cellular targets, including antigen presenting cells and virally infected cells. Deficiency in LFA-3 on EBV-transformed B cell lines have led to the hypothesis that this deficiency prevents' the necessary $\mathrm{T}$ cell binding required for proper immune surveillance

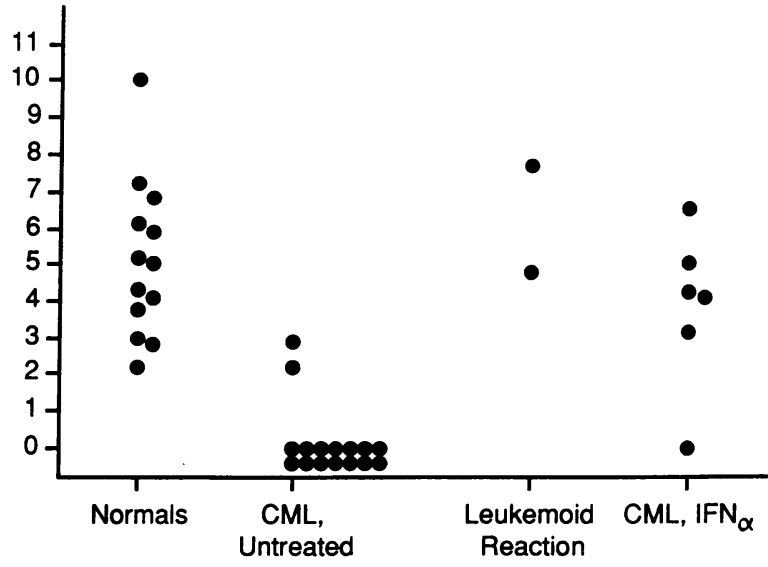

Figure 6. Irradiated CML progenitor cells fail to stimulate the proliferation of autologous T lymphocytes. Highly enriched CML or normal bone marrow progenitor cells were prepared by removing contaminating nonprogenitor cells ( $\mathrm{T}$ cells, B cells, NK cells, myeloid and erythroid precursors) by negative immunoselection on plastic dishes (28), and irradiated with $20 \mathrm{~Gy} .10^{5}$ autologous $\mathrm{CD}^{+} \mathrm{T}$ cells were incubated with $10^{5}$ irradiated progenitor cells for $8 \mathrm{~d}$, the cultures pulsed with ${ }^{3} \mathrm{HTdR}$ for $16 \mathrm{~h}$, and the cells were harvested. T cell proliferation was measured by the stimulation index, i.e., the ratio of ${ }^{3} \mathrm{H}$ incorporation into $\mathrm{T}$ cells stimulated with progenitor cells, versus ${ }^{3} \mathrm{H}$ incorporation into unstimulated $\mathrm{T}$ cells.

in vivo (14). Since LFA-3 is so widely expressed, clonal LFA-3 deficiency could lead to escape from $T$ cell-mediated detection and regulation of nonimmune cellular proliferation in a variety of tissues.

These observations suggest a direct role for interferon ${ }_{\alpha}$ reversible LFA-3 deficiency in the pathogenesis of stable phase CML. Cellular requirements for alloengraftment suggest that normal human bone marrow contains in the range of $10^{6} \mathrm{stem}$ cells, and hematopoiesis is maintained by the relatively balanced expression of multiple hematopoietic stem cell clones. If the cycling progenitor daughter cells of active stem cells are recognized and modulated by autoreactive T cells, then LFA-3 deficiency might allow CML progenitor cells to escape autorecognition and autoregulation. This would exacerbate even a slight intrinsic proliferative advantage by the CML clone. In this regard, the failure of highly enriched progenitor cells from patients with CML to stimulate autologous $\mathrm{T}$ cells proliferation is quite interesting, inasmuch as these autoreactive $\mathrm{T}$ cells locally suppress the differentiation of hematopoietic progenitor cells (21).

In this context it is noteworthy that paroxysmal nocturnal hemoglobinuria (PNH) cells are deficient in cell surface LFA-3 (24). While PNH and CML have disparate clinical manifestations, both share the feature that an abnormal clone gradually becomes overrepresented within the bone marrow. This shared deficiency suggests that LFA-3 deficiency might lead to overexpression of individual hematopoietic cell clones, not to elevated circulating blood cell counts per se. Whether the peripheral manifestation of the disease includes high white blood cell and platelet counts as in CML, or low blood cell counts and unusual hemolytic sensitivity as in PNH would depend on other pathophysiologic causes distinct from clonal expansion.

Deficient LFA-3 expression might be only one of several cytoadhesion deficiencies contributing to pathophysiologic 
clonal expansion in CML. Leukocyte alkaline phosphatase and LFA-3, both deficient in CML cells at different stages of differentiation, are two members of a class of membrane proteins which may be anchored to the cell surface by linkage to membrane lipids through phosphatidyl inositol $(25,26)$. Other such proteins include the adhesion proteins NCAM and decay accelerating factor (26). The data of Gordon et al. suggest that primitive hematopoietic cells may adhere to marrow stroma via phospholipase C-sensitive adhesion molecules $(11,12)$. While LFA-3 is expressed on most cells through both PI-linked and PI-independent forms $(26,27)$, it is possible that quantitatively decreased expression may both account for the results of our in vitro assays and prevent normal $T$ cell binding in vivo. The present data support the concept that CML cells may suboptimally express critical PI-linked stem cell proteins which mediate adhesion to stromal cells. Deficient expression of such proteins might contribute to the poor survival of CML marrow cultures in vitro and to failure to regulate CML clonal growth in hematopoietic niches in vivo. The present data both lend circumstantial support to such a hypothesis and suggest that IFN $_{\alpha}$-responsive CML cells might provide a suitable experimental system to isolate such critical adhesion molecules.

In summary, these data indicate that bone marrow progenitor cells from patients with CML fail to normally express cell surface LFA-3, and that this deficiency is ameliorated in vivo and in vitro by $\operatorname{IFN}_{\alpha}$. We hypothesize that this defect may contribute to the clonal advantage enjoyed by the CML stem cell progeny in vivo. Similar deficiencies in yet to be isolated stromal cell cytoadhesion proteins by CML progenitors may lead to the direct isolation of these molecules.

\section{Acknowledgments}

The technical assistance of Kelly Hardesty, Sebra Ellerson, and Robin Luttrel, and the secretarial assistance of Ms. Marty Davis is greatly appreciated.

Dr. Emerson was supported by a Scholarship Award from the Leukemia Society of America. This research was supported by PO1 CA 49639 as well as grants from the National Institutes of Health, the American Cancer Society (IM-580), the Kleberg Foundation, the Sid Richardson Foundation and the Gilson-Longenbaugh Foundation. We would like to thank Drs. Carol Clayberger and Alan Krensky for the generous gift of the TS2.9 antibody.

\section{References}

1. Nowell, P. C., and D. A. Hungerford. 1960. A minute chromosome in human chronic granulocytic leukemia. Science (Wash. DC). 132:1497.

2. Rowley, J. D. 1973. The $\mathrm{Ph}^{1}$ chromosome: evidence for a specific chromosomal translocation. J. Clin. Invest. 52:71a. (Abstr.).

3. Groffen, J., J. R. Stephenson, N. Heisterkamp, A. de Klein, C. R. Bartram, and G. Grosveld. 1984. Philadelphia chromosomal breakpoints are clustered within a limited region, bcr, on chromosome 22. Cell. 36:93-99.

4. Bernards, A., C. M. Rubin, C. A. Westbrook, M. Paskind, and D. Baltimore. 1987. The first intron in the human c-abl gene is at least 200 kilobases long and is a target for translocations in chronic myelogenous leukemia. Mol. Cell. Biol. 7:3231.

5. Heisterkamp, N., G. Jenster, J. ten Hoeve, D. Zovich, P. K. Pattengale, and
J. Groffen. 1990. Acute leukaemia in bcr/abl transgenic mice. Nature (Lond.) 344:251-253.

6. Whang-Peng, J., G. P. Canellos, P. P. Carbone, and J. H. Tjio. 1968 Clinical implications of cytogenetic variants in chronic myelocytic leukemia (CML). Blood. 32:755-766.

7. Vogelstein, B., E. R. Fearon, S. R. Hamilton, S. E. Kern, A. C. Preisinger, M. Leppert, Y. Nakamura, R. White, A. M. Smits, and J. L. Bos. 1988. Genetic alterations during colorectal-tumor development. N. Engl. J. Med. 319:525-532.

8. Delattre, O., S. Olschwang, D. J. Law, T. Melot, Y. Remvikos, R. J. Salmon, X. Sastre, P. Validire, A. P. Feinberg, and G. Thomas. 1989. Multiple genetic alterations in distal and proximal colorectal cancer. Lancet. ii:353-356.

9. Coulombel, L., C. Eaves, D. Kalowsek, C. Gupta, and A. Eaves. 1985. Long-term marrow culture of cells from patients with acute myelogenous leukemia. Selection in favor of normal phenotypes in some but not all cases. J. Clin. Invest. 75:961-969.

10. Talpaz, M., H. M. Kantarjian, K. McCredie, J. M. Trujillo, M. J. Keating, and J. U. Gutterman. 1986. Hematologic remission and cytogenetic improvement induced by recombinant human interferon alpha $\mathrm{A}$ in chronic myelogenous leukemia. N. Engl. J. Med. 314:1065-1069.

11. Gordon, M. Y., C. R. Dowding, G. P. Riley, J. M. Goldman, and M. F. Creaves. 1987. Altered adhesive interactions with marrow stroma of hematopoietic progenitor cells in chronic myeloid leukaemia. Nature (Lond.). 328:342-344.

12. Gordon, M. Y., D. Clarke, and M. F. Greaves. 1989. Haemopoietic progenitor cell-binding to the stromal microenvironment in vitro: similarities with N-cam-mediated adhesion. Exp. Hematol. (NY). 6:483a. (Abstr.)

13. DeChatelet, L. R., M. R. Cooper, and C. E. McCall. 1970. Absence of measurable leukocyte alkaline phosphatase activity from leukocytes of patients with chronic granulocytic leukemia. Clin. Chem. 16:798-799.

14. Gregory, C. D., R. J. Murray, C. F. Edwards, and A. B. Rickinson. 1988. Downregulation of cell adhesion molecules LFA-3 and ICAM-1 in Epstein-Barr virus-positive Burkitt's lymphoma underlies tumor cell escape from virus-specific T cell surveillance. J. Exp. Med. 167:1811-1824.

15. Wysocki, J. L., and V. L. Sato. 1978. "Panning" for lymphocytes: a method for cell selection. Proc. Natl. Acad. Sci. USA. 75:2844-2848.

16. Emerson, S. G., C. A. Sieff, E. A. Wang, G. G. Wong, S. C. Clark, and D. G. Nathan. 1985. Purification of fetal hematopoietic progenitors and demonstration of recombinant colony stimulating activity. J. Clin. Invest. 76:12861290.

17. Roth, M. S., J. H. Antin, E. L. Bingham, and D. Ginsburg. 1989. Detection of Philadelphia chromosome-positive cells by the polymerase chain reaction following bone marrow transplant for chronic myelogenous leukemia. Blood. 74:882-885.

18. Gubler, U., and B. J. Hoffman. 1983. A simple and very efficient method for generating cDNA libraries. Gene (Amst.). 25:263-269.

19. Saiki, R. K., S. Scharf, F. Faloona, K. B. Mullis, G. T. Horn, H. A. Erlich, and N. Arnheim. 1985. Enzymatic amplification of beta-globin genomic sequences and restriction site analysis for diagnosis of sickle cell anemia. Science (Wash. DC). 230:1350-1354.

20. Church, G. M., and W. Gilbert. 1984. Genomic sequencing. Proc. Natl. Acad. Sci. USA. 81:1991-1995.

21. Emerson, S. G., and J. H. Antin. 1989. Bone marrow progenitor cells induce a regulatory autologous proliferative $\mathrm{T}$ lymphocyte response. J. Immunol. 142:766-772.

22. Wallner, B. P., A. Z. Frey, R. Tizard, R. J. Mattaliano, C. Hession, M. E. Sanders, M. L. Dustin, and T. A. Springer. 1987. Primary structure of lymphocyte function-associated antigen 3 (LFA-3). The ligand of the T lymphocyte CD2 glycoprotein. J. Exp. Med. 166:923-932.

23. Seed, B., and A. Aruffo. 1987. Molecular cloning of the CD2 antigen, the T-cell erythrocyte receptor, by a rapid immunoselection procedure. Proc. Natl. Acad. Sci. USA. 84:3365-3369.

24. Selvaraj, P., L. Dustin, R. Silber, M. G. Low, and T. A. Springer. 1987. Deficiency of lymphocyte function-associated antigen 3 (LFA-3) in paroxysmal nocturnal hemoglobinuria. Functional correlates and evidence for a phosphatidylinositol membrane anchor. J. Exp. Med. 166:1011-1025.

25. Low, M. G., and A. R. Saltiel. 1988. Structural and functional roles of glycosyl-phosphatidylinositol in membranes. Science (Wash. DC). 239:268-275.

26. Dustin, M. L., P. Salvaraj, R. J. Mattaliano, and T. A. Springer. 1987. Anchoring mechanisms for LFA-3 cell adhesion glycoprotein at membrane surface. Nature (Lond.). 329:846-848.

27. Seed, B. 1987. An LFA-3 cDNA encodes a phospholipid-linked membrane protein homologous to its receptor. Nature (Lond.). 329:840-842. 